\title{
TU/e EmonONEN

\section{The distribution of pitch accents in instructions as a function of discourse structure}

Citation for published version (APA):

Terken, J. M. B. (1984). The distribution of pitch accents in instructions as a function of discourse structure. Language and Speech, 27(3), 269-290. https://doi.org/10.1177/002383098402700306

DOI:

10.1177/002383098402700306

Document status and date:

Published: 01/01/1984

\section{Document Version:}

Publisher's PDF, also known as Version of Record (includes final page, issue and volume numbers)

\section{Please check the document version of this publication:}

- A submitted manuscript is the version of the article upon submission and before peer-review. There can be important differences between the submitted version and the official published version of record. People interested in the research are advised to contact the author for the final version of the publication, or visit the $\mathrm{DOI}$ to the publisher's website.

- The final author version and the galley proof are versions of the publication after peer review.

- The final published version features the final layout of the paper including the volume, issue and page numbers.

Link to publication

\section{General rights}

Copyright and moral rights for the publications made accessible in the public portal are retained by the authors and/or other copyright owners and it is a condition of accessing publications that users recognise and abide by the legal requirements associated with these rights.

- Users may download and print one copy of any publication from the public portal for the purpose of private study or research.

- You may not further distribute the material or use it for any profit-making activity or commercial gain

- You may freely distribute the URL identifying the publication in the public portal.

If the publication is distributed under the terms of Article 25fa of the Dutch Copyright Act, indicated by the "Taverne" license above, please follow below link for the End User Agreement:

www.tue.nl/taverne

Take down policy

If you believe that this document breaches copyright please contact us at:

openaccess@tue.nl

providing details and we will investigate your claim. 


\title{
THE DISTRIBUTION OF PITCH ACCENTS IN INSTRUCTIONS AS A FUNCTION OF DISCOURSE STRUCTURE*
}

\author{
J.M.B. TERKEN \\ Instituut voor Perceptie Onderzoek
}

\begin{abstract}
Speakers gave instructions to listeners to assemble the front view of a house from a set of ready-made parts. The main aim was to find out how the distribution of accents over expressions referring to the parts of the front view was related to the structure of the monologues containing the instructions. Each monologue was analysed as a series of instructions, each instruction specifying to the listener what to do with one part of the front view (the TOPIC of the instruction). It turned out that the instruction was a meaningful unit of analysis: when topics were introduced into an instruction, the speaker always used accented expressions; afterwards the topic was often referred to by a pronoun. When the speaker mentioned other parts of the front view in the course of an instruction, he mostly used the names of the parts; most of these names were accented, though more often when they were used for the first time in an instruction than when they were used later on. The results were interpreted to mean that the speakers used accentuation to signal to the listener the degree of availability of the information conveyed: an accented exprescion signals to the listener that he cannot easily map the expression onto the information it refers to in the context; an unaccented expression signals to the listener that he can map the expression directly onto the intended information, since the information at that point in the utterance may be supposed to be maximally activated due to the preceding context. Some consequences were considered for the listener's processing of the incoming information.
\end{abstract}

\section{INTRODUCTION}

In normal speech, some words are more prominent than others. Phonetic investigations have related differences in prominence to acoustic correlates such as amplitude, duration, fundamental-frequency $\left(F_{0}\right)$ peak and $F_{0}$ movement (e.g., Lehiste, 1970). Since these parameters are under the control of the speaker, it is reasonable to ask why speakers make some words more prominent. An answer to this question not only sheds light upon the speech-production system, but might also be useful in designing text-to-speech systems.

Investigations of Dutch intonation ('t Hart and Cohen, 1973; 't Hart and Collier, 1975) have shown that the main .way for making words prominent in Dutch is to pronounce them with a clear pitch rise or pitch fall on the lexically stressed syllable of

- This investigation is part of a more comprehensive project on the comprehension and production of descriptive language, in cooperation with the Max Planck Institut für Psycholinguistik, Nijmegen. The project was funded by the Netherlands Organization for the Advancement of Pure Research, Grant 07-35. The author is very grateful to G. Doodeman and E. Truin for technical assistance and data collection, and to Dr. S.G. Nooteboom and Dr. A.J.M. Houtsma for help in giving shape to various drafts of the paper. 
the word. We will therefore use the term "pitch accent" instead of "prominence," or simply "accent." Since the choice between rising and falling movements seems to be dictated mainly by positional constraints, we will not look for functional distinctions between rises and falls, but treat them as equivalent means for accenting words.

In looking for the factors governing the assignment of pitch accents to words, linguistic investigations have proposed both grammatical and non-grammatical determinants. Important grammatical factors are, for instance, word class and word position (e.g., Bresnan, 1972; Chomsky, 1971, O'Shaughnessy, 1976). But a purely grammatical account is insufficient, since, as has often been noted, one sentence can have several distributions of accents. The following example shows that this has to do with the context of the sentence; if a word which for grammatical reasons should be accented (cf. (1)) is mentioned in the preceding context, it remains normally unaccented (cf. Bolinger, 1972; Chafe, 1974; Halliday, 1967) (cf. (2)):

(1) (we do not often visit public events but) we went to the theatre yesterday

(2) (we do not often visit the theatre but) we went to the theatre yesterday

(Accented words are italicized.)

Such claims have received experimental support among others from GoodenoughTrepagnier (1977).

Another non-grammatical factor that may affect the distribution of accents is the nonlinguistic context (cf. Schmerling, 1976). The relation between grammatical and nongrammatical factors might best be considered such that non-grammatical factors modify syntax-based patterns of accentability; that is, listeners interpret actual accent patterns relative to their knowledge of the grammatical rules (cf. Ladd, 1978). Our present concern will be with the non-grammatical factors.

In an earlier attempt to explore the factors causing speakers to accent some words rather than others (Nooteboom and Terken, 1982), we performed an experiment in which speakers gave descriptions of successive changes in a letter configuration displayed on a screen. The descriptions generally had the following form: "The $p$ moves to the right of the $k$." By selecting the appropriate changes we could influence the content of the successive utterances. We obtained the following results:

- if a letter name had not been mentioned in the preceding utterance, it was generally accented;

- if a letter name was repeatedly mentioned in successive utterances in the same sentence position, the probability that it would be accented dropped with increasing frequency of mention;

- letter names in subject position (always coinciding with sentence-initial position) were less often accented than letter names in predicate position (coinciding with sentencefinal position); 
- the presence or absence of accent was an option for nominal expressions: speakers hardly ever used pronouns.

We have interpreted these results in terms of the following hypothesis: the speaker's decision to accent or deaccent words depends on whether or not he judges their interpretation to be already available to the listener. "Available" denotes the ease or speed with which the intended interpretation can be accessed by the listener: speakers do not accent words when their interpretation is judged highly available; they do accent words when their interpretation is judged to be relatively unavailable to the listener. Such a hypothesis would make sense if, as psycholinguistic investigations have shown, accents draw the listener's attention (cf. Cutler, 1976; Cutler and Fodor, 1979): attention is directed to words requiring most processing. The factors taken into consideration by the speaker in determining whether an intended interpretation is available to the listener or not may then be summarized as recency of mention, frequency of mention, and factors guiding the selection of an expression for subject function or initial position (cf. Ertel, 1977; Osgood and Bock, 1977).

It is quite possible, however, that these findings and conclusions have rather limited applicability to other types of discourse, since the communicative task in the experiment had some rather atypical features when compared with other discourse types:

- each change was described in one short utterance;

- due to the nature of the information to be transmitted, there was only a weak coherence between utterances: the utterances constituting a monologue could be reshuffled without affecting the monologue's coherence;

- in describing a change, a speaker did not yet know what he would be saying in the next utterances, since he did not know what was going to happen next.

This type of discourse may be represented as in Figure 1a; it can be seen that the utterance is the basic building block of the monologue. In most types of discourse, an utterance combines with other utterances to form larger discourse structures (such as paragraphs), as in Figure $1 \mathrm{~b}$; or, in other words, the coherence between utterances is not equally strong at all utterance boundaries. (We define coherence as the degree to which the interpretation of an utterance is dependent on the interpretation of the preceding utterance, or, put differently, the degree to which an utterance restricts or affects the interpretation of the succeeding utterance.) To find out whether discourse structure indeed affects the influence of the factors mentioned above, we used a less stringent task in the experiment to be reported in this study. Speakers were allowed to determine themselves the order in which information was to be presented and the number of utterances they used. We hoped in that way to elicit monologues with a structure resembling structure (b) in Figure 1 more than (a).

We may then ask the following questions:

- Does the probability of accentuation decrease with each additional reference to a referent, or is the probability of accentuation of expressions referring to the same referent in successive utterances affected by the degree of coherence between 
(a)

MONOLOGUE

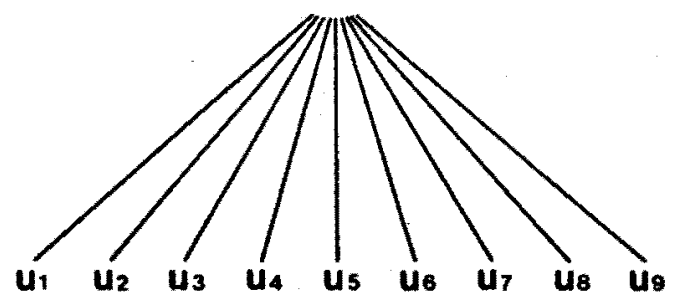

(b)

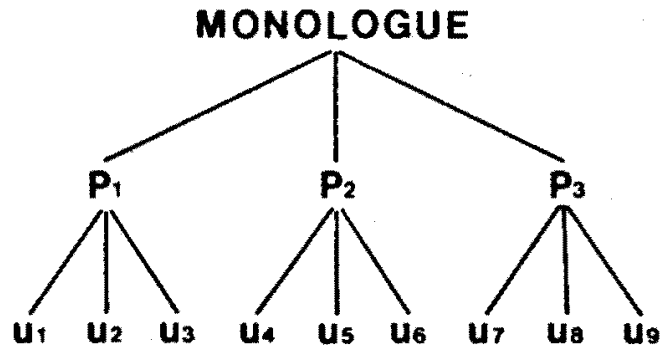

Fig. 1. Two possible discourse structures. (a) Purely linear structure, as realized in earlier experiments (Nooteboom and Terken, 1982). (b) Structure more representative of planned monologues: utterances combine to form larger discourse units. The present task was intended to elicit monologues with a structure like (b).

utterances?

- Is mention in the immediately preceding utterance critical for deaccentuation of a referring expression?

- What is the contribution of syntactic role or sentence position?

- What is the relation between word class and the distribution of accents?

\section{METHOD}

\section{Task}

The experimental task was the following. A speaker gave a listener instructions to 
assemble a two-dimensional representation of the front view of a house from a set of ready-made pieces of cardboard. The speaker and the listener had identical sets of elements at their disposal. The speaker could not see or hear the listener during the task, so that the speaker received no feedback about how clear his instructions were; he had to decide for himself when he had given enough information to the listener for proper execution. This was done for two reasons: the speaker would not interrupt his utterances on the basis of his watching the listener perform a certain action; nor would the listener's contributions influence the information structure of the speaker's utterances. A secondary advantage was that potential conversational uses of accentuation (e.g., as a turn-taking device) could not influence the distribution of accents.

\section{Material}

The material consisted of two sets of ready-made pieces of cardboard. Each set contained the following pieces: a. front (in uniform black); b. roof; c. front door; $d$. small window for front door; e. window for living room; f. curtain for living room window; g. plant for living room window; h-i. two windows for bedrooms; j-k two curtains for bedroom windows; 1 . attic window; $m$. tree. The name of each piece was written on the back, in order to prevent identification or labelling problems. The resulting front view measured 20 by $35 \mathrm{~cm}$. Figure 2 shows the set of pieces and a possible realization of the front view.

\section{Subjects}

Eleven speakers participated in the experiment: five male and three female employees of the Institute for Perception Research, and three women not associated with the Institute, who were paid for their participation. All were native speakers of Dutch. The listener was in most cases a research assistant.

\section{Procedure}

The speaker and listener were introduced to each other, and the instructions were read to both together, in order to let the speaker know what information the listener had about the communicative situation. They were told that the experiment concerned how speakers give instructions, and that the instructions concerned the assembly of the front view of a house. Since the speaker could not see or hear the listener, he had to be sure to give the listener as much information as he or she needed to perform the task adequately. The speaker was told that he could use the labels on the back of each piece, and that he could keep track of the state of affairs by applying his instructions to his own set of pieces. There was no criterion set for correct performance.

Additional questions were answered. If there were no more questions, the speaker was seated in an Amplifon silent cabin on a chair at the table. The unordered set of pieces was already on the table. The listener was seated at a table outside the cabin so that he could not be seen by the speaker. There was a microphone suspended in the cabin, and the listener heard the speaker's voice through headphones. The speaker's utterances were also recorded on tape for later analysis. 
(a)

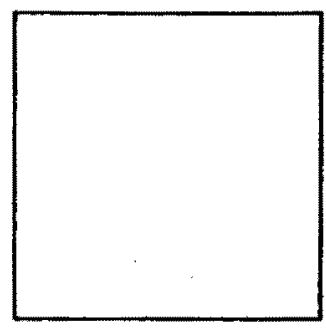

(a)
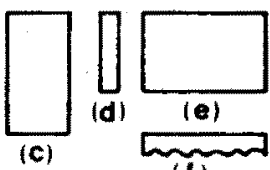

(f)

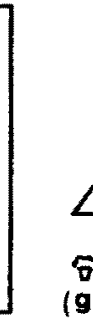

(9)

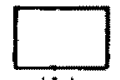

(n)

masting

(j)

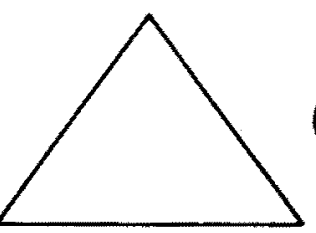

(b)

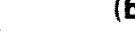

\section{(9)}

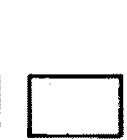

(i)

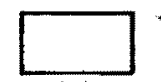

(1)

(b)

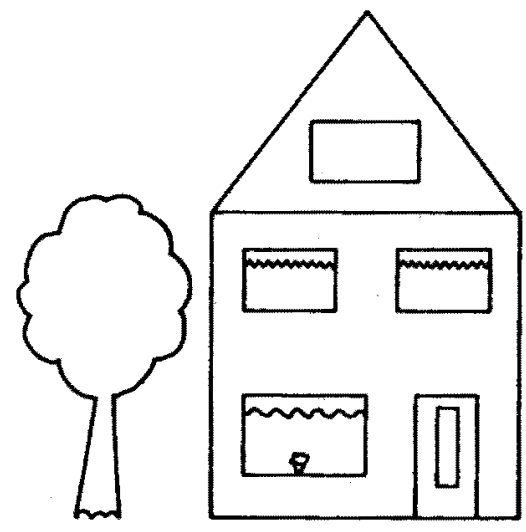

Fig. 2. The set of pieces for the assembly task, and a possible realization of the front view.

\section{METIIOD OF ANALYSIS}

\section{Accentuation analysis}

The recorded monologues were typed out and analysed for pitch accents. The location of pitch accents was determined in the following way. The author listened to each 
utterance and estimated the best fitting pitch contour in terms of the perceptually relevant pitch movements defined by Collier and 't Hart (1981), whose notational system was used for writing these pitch contours down on the typed versions of the monologues. The resulting monologue transcriptions were then checked by a second phonetician trained in intonation analysis and acquainted with the notational system, who compared the transcriptions with the original utterances and suggested modifications when necessary. The number of disagreements was rather small. From the resulting transcriptions the locations of pitch accents were derived.

This procedure allows us in principle to examine the appropriateness of the transcriptions. Resynthesis of the utterances and comparison with the original utterances would be a check on whether or not they are indeed equivalent. Since this stage is very time-consuming, the analysis has been restricted to the procedure outlined above.

\section{Discourse analysis}

In total, 11 monologues were collected. The number of words per monologue ranged from 219 words for the shortest monologue to 799 for the longest. Part of a sample monologue is reproduced below (slashes are used to facilitate segmentation in reading and are not meant to indicate utterance boundaries). Accented words are italicized (italics in the English transation should not be seen as a proposal about accentuation in English):

(3) 1. dan hebben we het zwarte vierkant then we have the black square

2. daar gaan we nu een dak opzetten/dat is het groene driehoek/ now let's put a roof on it/ that is the green triangle/ de grote groene driehoek/die zetten we er boven op the large green triangle/ we place that on top of it

3. dan pakken we het woonkamerraam/dat draaien we met de then we take the living room window/we turn this coloured kleurzijde om en leggen het links onderin met wat nimte side $u p$ and lay it bottom left leaving some space eronder/zodat de lange kant evenwijdig ligt aan de onderkant underneath it/so that the long side is parallel to the

van het huis

bot tom of the house

4. dan pakken we de voordeur en die zetten we een eindje rechts then we take the front door and we put that a little to the van het raam met de korte zijde naar onder right of the window with the short side down

5. dan gaan we een gordijn aanbrengen in het woonkamerraam/dat 
then we'll place a curtain in the living room/

that

gordijn heeft uhh ... golfjes aan de onderkant/dat leggen we

curtain has uhh ... woves at the bottom/ we put that at the

aan de bovenzijde op het ram

top of the window

Thematic structure. We will use the term "thematic structure" to refer to the structuring of discourse in terms of what is spoken about and what is said about it, and the relations between successive issues spoken about. We take the instruction as the basic unit of thematic structure. Each instruction contains the information needed to bring one element of the set of pieces into place. This piece is labelled the TOPIC of the instruction (examples are the black square, the roof and the living room window in (3) $1-3$, respectively). The criterion for identifying instructions is the introduction of a new topic into the monologue. The topic of an instruction is therefore in the present approach determined on the basis of the non-linguistic task structure. An instruction may mention several other referents besides the topic. We will label these referents non-topics (examples are the black square in (3) 2 and (3) 3, and the living room window in (3) 4 and (3) 5). Linguistic expressions corresponding to topical and non-topical referents will be labelled topical and non-topical expressions, respectively.

For our purposes here, an instruction is defined to begin at the onset of an utterance introducing a certain topic until the onset of an utterance introducing another topic. We will assume that the degree of coherence in general is smaller between instructions than between utterances within instructions.

It should be noted that the notion of topic as it is used here differs from what is understood as "topic" by most linguists. Our TOPIC is a referent, whereas most linguists define the topic as a sentential phrase. Secondly, most linguists do not consider expressions that topicalize a referent to be topics themselves, whereas we consider phrases introducing the new topic as topical expressions too. Our notion of topic resembles the notion as it is used by authors in the field of discourse and conversation analysis (e.g., Grosz, 1978; Linde, 1977; Reichman, 1978). The main reason for relating thematic structure to the task structure is that we need not define formal linguistic criteria for identifying topics.

Not all linguistic material falls under the heading of instruction. For instance, speakers begin with ordering the set of pieces for themselves; also speakers may at some point during the monologue make explicit some consequence of what has already been said in a preceding instruction. These contributions have not been considered in the analysis.

Some speakers noted, while giving an instruction, that they had made an error, and subsequently chose another continuation of the instruction. These instructions were excluded from analysis. Also, some instructions deviated from other instructions in that they started with a complex topic (for instance two windows) and then in the course of an instruction concentrated on the individual components. These were excluded from analysis as well. Finally, the complete monologue of one speaker was discarded, because we could not determine the exact points at which the respective topics were introduced, 
and because he produced a number of intonation contours which could not be accounted for with the criteria of Collier and 't Hart (1981).

Types of referring expressions. In the analysis we have restricted ourselves to expressions referring to pieces of the set constituting the front view. A referring expression can take several forms. We distinguish the following categories:

a. Full referring expression, which enables the listener to pick out the intended referent on the basis of the lexical information contained in the expression. Not all expressions refer precisely to one piece. For instance, consider the following expressions:

(4) 1. the curtain of the bedroom window

2. the curtain bedroom window ("of the" deleted)

3. the bedroom window curtain (compound)

Whereas the last expression clearly refers only to the curtain, one might defend the idea that the first expression refers to two pieces (curtain and bedroom window). But then what about the second expression? To simplify matters we take such expressions to have only one referent (i.e., the curtain).

b. Incomplete reference: We have labelled referring expressions incomplete when they are neither "full" nor "pronoun," but somewhere in between. Examples are "the red one" and "that thing."

c. Pronoun: In general, this category presents no problems.

d. Implicit reference: In a number of cases the speaker does not mention the intended referent but uses an expression which requires the listener to determine himself the appropriate referent. An example is "the left side" instead of "the left side of the front." We label these cases ellipsis, though not all cases involved are real cases of ellipsis (in real cases of ellipsis the underlying form constitutes a grammatical phrase). A number of cases of ellipsis are irrelevant to our interest. They pertain mainly to ellipsis of first terms in coordinations, such as "to the left and to the right of the front door," and to references to the horizontal and vertical axes (e.g., "from left to right"). The relevant cases mostly take one of the following forms:

"the left side" instead of "the left side of the window," and

"to the left" instead of "to the left of the front door."

The main reason for including these cases of ellipsis/implicit mention is that in a number of cases when the speaker refers to a referent in an instruction the first time, he does so implicitly.

A referring expression is taken to be accented when at least one syllable in the expression is accented. Thus, both

(5) dit slaapkamerraam (this bedroom window)

and 
(6) dit slaapkamerraam (this bedroom window)

are taken to be accented. The main reason for doing so is that we are interested primarily in factors that make speakers use unaccented expressions as opposed to accented expressions, that is, expressions carrying no accent as opposed to expressions carrying one or more accents. (Later on we will return to this distinction and see that it is not always satisfactory.)

\section{RESULTS}

We will first give the general results and consider the questions raised in the introduction; then we will consider two categories deviating from the general tendencies. Finally, we will consider a category of cases where the distribution of accents within the referring expression renders the dichotomy of ACCENTed and DEACCENTed expressions unsatisfactory.

First we have counted the number of accented and unaccented full expressions and pronouns, and the number of implicit references as a function of Topic/Non-topic and First/Later mention in instruction. The data are shown in Table 1. The general pattern is as follows:

1. When a speaker introduces a new topic, he nearly always uses an accented full expression.

2. Once the topic of an instruction has been introduced, there is a considerable decrease in the number of accented expressions. When a speaker uses an unaccented expression, he mainly uses a pronoun.

3. When a speaker mentions a non-topical referent for the first time in an instruction, he is likely to use an accented full expression, but less often than in the case of topical referents.

4. The main way of referring to non-topical referents that have already been introduced into an instruction, is either by means of a full accented expression or by implicit reference.

As the results show, the majority of expressions referring to the already introduced topic of an instruction are unaccented, and these account for the majority of unaccented expressions; that is, in general there is a tendency for expressions referring to the already introduced topic of the present instruction to be deaccented, and for other expressions to be accented. We will now consider how these data answer the questions raised in the introduction.

The first question raised at the end of the introduction concerned the effect of frequency of mention. If the probability of accentuation is a function of serial position, we would expect a gradual decline with each additional mention. On the other hand, if what counts is not simple repetition but rather the way utterances relate to each 


\section{TABLE 1}

Distribution of accented and unaccented expressions and implicit references to elements of the house as a function of whether the expression refers to the topic of the instruction or not, and whether the referent is mentioned for the first time in the instruction or not

+ ACCENT -ACCENT

TOPIC

FIRST

MENTION
110

\begin{tabular}{ccc}
\hline full & incompl & pro \\
109 & 1 & -
\end{tabular}

2

\section{ELLIPSIS/IMPLICIT \\ REFERENCE}

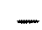

full incompl pro

$2-$

13

17

\begin{tabular}{cccccc}
\hline full incompl & pro & full incompl & pro \\
104 & - & 1 & 6 & - & 7 \\
\hline
\end{tabular}

119

47

\begin{tabular}{cccccc}
\hline full & incompl & pro & full & incompl & pro \\
69 & 5 & 15 & 11 & 2 & 106 \\
\hline
\end{tabular}

27

51

87

NON-TOPIC

full incompl pro

\begin{tabular}{lccccc}
\cline { 5 - 6 } full & incompl & pro & full & incompl & pro \\
84 & - & 3 & 21 & - & 6 \\
\hline
\end{tabular}

other (the thematic structure of the discourse), we would expect two things: 1. high probabilities of accentuation after points of low coherence (that is, after instruction boundaries) and low probabilities of accentuation after points of high coherence (within instructions); 2. differences for topics and non-topics since utterances within instructions are thought to be coherent primarily by virtue of being about the same topic.

Figure 3 gives the relevant data. As can be seen, there is no gradual decline in the probability of accentuation with serial position. Instead, the probability of accentuation is high for first mention in the instruction and thereafter remains at the same low level; secondly, this effect is more marked for topical than for non-topical expressions.

The second question concerns the effect of recency of mention on the probability of accentuation. Unfortunately, our data do not allow a direct answer since the number 


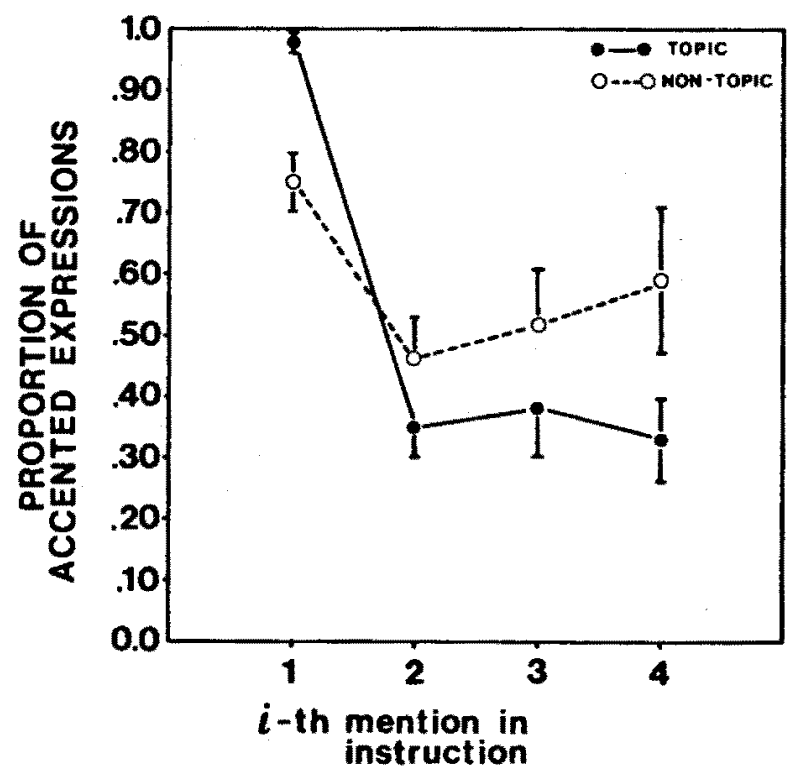

Fig. 3. Proportions of accented expressions as a function of frequency of mention of the same referent earlier in the instruction, for topic of instruction and nontopic. For non-topics only cases have been included where only one non-topical referent was mentioned in the instruction. For each data point \pm 1 standard error of the proportion, defined as $s_{p}=\frac{P(1-p)}{N}$, is indicated with a vertical line.

of relevant cases is rather small: within instructions, there are only a few cases where referents are not mentioned in each utterance; between instructions, there are only a few cases where a referent is mentioned in two successive utterances. However, inspection of the data reveals that both within and between instructions deaccentuation of nontopical referents hardly ever occurs, when the referent has not been mentioned in the immediately preceding utterance, whereas deaccentuation does occur when the referent has been mentioned in the preceding utterance, even when the intervening utterance boundary is also a boundary between instructions. This observation suggests that recency may indeed affect the probability of accentuation. On the other hand, expressions referring to the house itself are often deaccented, even though the house has not been mentioned over long stretches of discourse.

The third question to be considered is whether differences in probability of accentuation are associated with differences in grammatical role or with differences in the position of the expression in the clause. To answer this, we have considered all clauses 


\section{TABLE 2}

Relation between accentuation and sentence position/grammatical function. Number of accented and unaccented expressions as a function of (a) sentence position; (b) grammatical function. (c) Dependence between sentence position and grammatical function. (d) Number of accented and unaccented expressions as a function of grammatical function for seutence-initial position only

(a)

$$
\text { +Accent -Accent }
$$

Sentence-initial

position

63

91

Not initial

position

293

62

(b)

+Accent -Accent

Grammatical subject

.31

47

Not subject

325

106

(c)

Subject

Sentence
initial

Not

69

initial

Not subject

85

346

(d)

$$
\text { +Accent - Accent }
$$

Sentence-initial only

Grammatical subject

27

42

Not subject

36

49

containing finite verbs, so that it is relatively easy to assign expressions to grammatical role and clause positions (the order of referring expressions can be more naturally related 


\section{TABLE 3}

Relation between accentuation and word class. Number of accented and unaccented expressions as a function of whether the expression is a nominal or pronominal expression

Full (nominal)

Pronominal
+Accent

366

19
-Accent

40

119

to the domain of the clause than to the domain of the utterance). Again, we have only considered expressions referring to elements of the house, thereby excluding references to the participants in the communication ("I," "you," "we") which (if present) generally occupy subject position.

Table 2 gives the relevant data. In testing the contributions of grammatical role and sentence position, we find that they both affect the probability of accentuation $\left(x^{2}{ }_{1,509}\right.$ $=40.0 ; x_{1,509}^{2}=88.5$, respectively). Also, there is a strong relation between position and grammatical role $\left(x_{1.509}^{2}=147.9\right)$ : subjects occur more often in initial position than non-subjects. For initial position, however, the probability of accentuation of expressions is independent of grammatical role $\left(x^{2}{ }_{1,154}=0.16\right)$.

The fourth question concerns the effect of word class: do speakers use deaccentuation as an option more or less independent of the choice between nominal and pronominal expressions, or are the two options associated? As Table 3 shows, accented expressions are mostly open class words, unaccented expressions are mostly pronouns $\left(\mathrm{x}_{1,544}=\right.$ 286.8).

The results suggest that the instruction is a meaningful unit of analysis as the basic building block of thematic structure. Thematic structure does not have an all-or-none effect, however; there are two categories of deviations from the general pattern. These we will consider now.

Accented expressions referring to the current topic

Out of the 89 accented topical expressions at later mention, 21 are full expressions giving an additional specification of the topic immediately after the topic has been introduced, such as in example (7).

(7) then we take the front door that is the red rectangle

Such additional specifications might be considered to be part of the topicalization procedure (including topic shift).

The function of topic shift as part of the topicalization procedure might also account 
for 12 of the 14 accented pronouns, which occur immediately after the current topic has been introduced, as in (8).

(8) we take the living room window we put that in ...

(The other cases of accented pronouns are part of identifying clauses providing the additional specifications considered above).

Of the remaining 54 cases, there are eight accented topical expressions that are part of an explicit double contrast, as in (9).

(9) ... so that the short side of the front door is against the bottom of the black square ...

A number of other expressions might also be accented for reasons of contrast, but we have chosen not to include these cases, since it is hard to identify them on structural grounds. Still other expressions are accented for a variety of reasons, such as selfcorrection and repetition of an expression including its intonation contour. But a number of expressions are accented for no apparent reason. In most of these cases it is possible to drop the accent without resulting unacceptability.

\section{Deaccented non-topical expressions}

We find unaccented expressions referring to non-topical referents both at the beginning of instructions and later on. Those at the beginning of instructions $(n=9)$ generally refer to the topic of the immediately preceding utterance, and seven of these occur in initial utterance position. Deaccented non-topical expressions later on in the instruction are generally involved in a contrastive relation, although it is again problematic to identify them on structural grounds.

\section{Heads and modifiers}

So far, we have simply considered the distribution of accents over referring expressions. That is, we have simply taken both of the following to be accented.

(5) this bedroom window $(\mathrm{N}=338)$

(6) this bedroom window $(\mathrm{N}=28)$

These are not free variants: when the speaker introduces a new topic, the head noun of the expression is nearly always accented. There are 12 cases (out of 112 cases of topic introduction) where the head noun is not accented. In seven of these the speaker had introduced in an earlier part of the monologue another topic with the same name or shape (four other cases concern the use of head nouns such as "piece"). Compare the following example:

(10) 1. we nemen een slaapkamerraam/dit plaatsen we in de we take one bedroom window/we place this along the lengterichting longitudinal axis 
2. we nemen het andere slaapkamerraam we take the other bedroom window

Although the new topic in (10) 2 is mentioned for the first time in the monologue, the semantic category "bedroom window" has been used to refer to the topic of the preceding instruction.

Deaccentuation of the head noun of a referring expression does not only occur when the semantic category has been mentioned in the immediately preceding instruction. Sometimes there is an intervening instruction as in the following examples:

(11) 1. dan gaan we een gordijn aanbrengen in het woonkamerraam then we place a curtain in the living room window

2. dan pakken we het dakraam then we take the attic window

3. en daar brengen we ook een gordijn op aan and on it we also place a curtain

In (11) 3 "a curtain" is deaccented and corresponds to "a curtain" in (11) 1 .

(12) 1. dan pakken we een slaapkamerraam then we take a bedroom window

2. dan brengen we een rood gordijn aan then we place a red curtain

3. dan rechts daarvan het andere slaapkamerraam then to the right of it the other bedroom window

In (12) 3 "the bedroom window" is deaccented and corresponds to the phrase "a bedroom window" in (12) 1 .

\section{Discussion}

We have started from the hypothesis that the presence or absence of an accent on a referring expression depends on whether - in the speaker's opinion - the referent is available to the listener. The results suggest that the speaker's judgments regarding the availability of a referent is sensitive to the thematic structure of the discourse.

1. Within an instruction, the probability of accentuation does not show a gradual decline as the number of references to a referent increases. Rather, there is a considerable decrease from the first to the second reference; after the second reference there is no further decrease. Also, these probabilities reach more extreme values for topical than for non-topical expressions.

2. Across instruction boundaries, there seems to be no carry-over of estimated 
availability: the probability of accentuation of a non-topical expression does not depend on whether the referent has been mentioned in the preceding instruction. There are two notable exceptions to this generalization: firstly a new instruction may open with an unaccented expression referring to the topic of the immediately preceding instruction; secondly, when the speaker refers to the house as a whole, he often uses an unaccented expression, regardless of whether the house has been referred to earlier in the same instruction, or in the preceding instruction.

The role of thematic structure also shows up in the following:

3. Speakers preferably put unaccented expressions in utterance-initial positions. This finding supports the often proposed association between early sentence position and referential information already available from the context (often referred to as the GIVEN-NEW ordering, cf. Halliday, 1967; Clark and Haviland, 1977; Bock and Irwin, 1980). Combined with the fact that most unaccented expressions are topical expressions, this illustrates the fact that topicality and GIVENness are often associated (cf. Goodenough-Trepagnier and Smith, 1977).

4. Speakers prefer to use pronouns to refer to the topic of an instruction once it has been introduced into the instruction (comparable findings have been reported by Reichman (1978), Linde (1977), Marslen-Wilson, Levy and Tyler (1982), and by KarmiloffSmith (1981) for children).

That thematic structure is taken into consideration in judging the availability of a referent also becomes clear when we follow the course of an instruction. Let us take the end of the previous instruction as a starting point, when the topic of that instruction is still in the focus of attention (that is, is still the most available referent).

When the speaker introduces a new topic into the discourse, the referent must be given preferential status in the listerer's discourse model. Generally, this takes the following form: the speaker makes the expression introducing the new topic very prominent, and uses syntactic means to signal topic shift ("and then ... "). There is hardly any exception to the rule that such introductory phrases are marked by accentuation; in general, the noun and whatever adjectives are present are accented. (When the new topic belongs to the same semantic category as the topic of the preceding instruction, the word expressing the category is generally deaccented, implying that deaccentuation also occurs when the meaning of a word is judged to be available rather than the intended referent (cf. also Pechmann, 1981). However, since the referent itself is not available, the speaker must somehow accent another word by default (cf. Ladd, 1978). This problem can be solved in two different ways: (1) if the referring expression contains other accentable words, these other words may be accented by default (such as in "the green window" after "the blue window"); (2) if there are no words left to carry the pitch accent, some other word may be inserted specifically to carry the pitch accent, and to indicate that the current referent in some respects is identical to the preceding topic (such as in "the other bedroom window" after "a bedroom window"). This observation suggests that accentuation requirements interact with the choice of words used to code the information.) 
In addition, the new topic may be given high availability relative to the other referents by further specifying its properties (among other things, this lengthens the time the listener is concentrating on the new topic). The expression containing the additional specification presents information not yet available and is accordingly marked by accentuation; again, as a rule, the noun and whatever adjectives are present are accented.

The use of accented pronouns immediately after topic introduction seems to be another way to confirm for the listener the fact that there has been a topic shift.

From this point on the new topic is the referent with the highest degree of availability, and we may suppose there to be a corresponding decrease in the availability of other referents. This explains why expressions referring to referents other than the topic are generally accented when they are mentioned for the first time in the instruction, even though they may have been mentioned fairly recently (an exception is the case where the speaker relates the present topic to the topic of the preceding instruction: in that case the speaker often uses an unaccented expression to refer to the preceding topic, generally as the first expression in the instruction).

As the topic is the most available referent of all, the speaker may use unaccented expressions; in general, he uses an unaccented pronoun to refer to the topic; this suggests that lexical information is judged redundant for determining the intended referent (cf. Marslen-Wilson, Levy and Tyler, 1982, p. 365).

There are, however, a number of cases where the speaker accents topical expressions. Why would he do so? We will first consider the effect of contrast.

If what matters for deaccentuation is the availability of a referent relative to the present state of the listener's discourse model, we would expect that a topical expression which is part of a contrastive construction, such as those we have considered in the results section, would generally be unaccented. This proved not to be the case. Such expressions are probably accented because the speaker wants to focus the listener's attention on the contrasting elements (Chafe, 1974); that is, the distribution of accents in the initial part of a contrastive construction is determined more by relations with what he will say later on, than (as in other uses of accentuation) on relations with the preceding linguistic context. One might suggest that this account of contrastive accentuation should be generalized to all cases of accentuation; one argument in favour is that it is not possible to make a clear distinction between what is and what is not contrastive. We will not analyse this possibility in more detail.' (Although topic-hood

1 Some authors consider all uses of accent in context as indicative of contrast, where the actual referent is contrasted with the other ones possible at that moment, or the others the speaker is thinking of (Keijsper, 1982; Thorsen, 1980). If one prefers to look upon it in that way, the present investigation might be considered as focusing on the question of how context affects whether for the speaker a referent is the only one coming into view, or whether there are more, in the course of formulating what he will say. Of course, the question of how the context delimits the set of alternative candidates cannot be answered without taking into consideration the thematic structure of the discourse. Moreover, it is not clear what predictions may be derived from such a theoretical proposal regarding the influence of accentuation on the listener's comprehension. 
does not seem to affect the distribution of accents in contrastive constructions, its influence shows up in other ways: (1) generally, the topic is mentioned before the other referent involved; (2) often, the topic is mentioned implicitly.)

Secondly, there are topical expressions in the course of an instruction that are accented for no apparent reason. However, since there is a strong relation between word class and the presence or absence of an accent, one might suggest that in these cases local, syntactic considerations (the tendency to accent a noun just because it is a noun) override global, contextual considerations (the decision to deaccent a word that refers to an available referent). The strong association between the presence or absence of accent and word class might derive from the "reluctance" to use nouns in informal speech situations, that is, the tendency to use nouns only when the speaker refers to unavailable information, and to use pronouns to refer to available information.

Since the information in an instruction is by definition relevant to the topic, not with respect to other referents, one might expect the estimated availability of non-topical referents to remain relatively low in the course of an instruction, even when they are mentioned repeatedly. This accounts for the finding that there is no sharp reduction in the probability of accentuation for non-topical referents from the first to the second mention in the instruction. On the other hand, since all of the discourse is relevant to the assembly of the house (which may be considered to be the "discourse topic"), the availability of the referent 'house' may be judged high throughout the discourse. This explains why recency considerations do not play a role for the "discourse topic" house.

If accented expressions are generally used to refer to unavailable information, one might ask what the communicative functions are of the presence or absence of pitch accents on referring expressions. Representatives of the Form/Content analysis approach have related the presence of an accent to High Deixis and the absence of an accent to Low Deixis (Garcia, 1977; Kirsner, 1979). High Deixis here signifies "greater urging that the hearer find the referent" and Low Deixis signifies "lesser urging that the hearer find the referent," that is, Deixis is given primarily "instructional" meaning (Kirsner, 1979, p. 373). Ladd (1978) associates absence of accent with "shifter," that is, an expression the meaning of which is to be interpreted with respect to another part of the discourse. However, our proposal to associate accentuation with availability seems to lead to more specific predictions about how the presence or absence of an accent might affect the listener's processing of the incoming speech: if we assume that a listener needs less time to locate referents that are immediately accessible than to locate referents that are not, the absence of an accent on a referring expression may signal to the listener that he should try out first that potential referent for a referring expression that is most available at that point in the utterance, or, if the listener has already found a potential referent, that he has probably taken the right one.

Thus, the appropriate distribution of accents would help the listener to effectively allocate processing resources at each point in the utterance. To illustrate how this might go about, take the following example:

(13) take the living room window and put it to the left of the front door so that the upper side of the li... 
If the syllable $l i$ - is unaccented, the listener may simply take the topic (living room window) as the intended referent, or he may have already done so on the basis of the earlier part of the utterance. In either case he may perform only a superficial analysis of the next speech segments to see whether they match his expectations and allocate processing resources to other activities, such as integration. Predictions following from these suggestions will be investigated in subsequent research.

There are two points which we have not considered, and which may nevertheless be relevant to the results of the present investigation.

1. Our definition of topics, and the decision to take the instruction as the primary unit of thematic structure, may have concealed factors which are relevant to the distribution of accents, and which would have shown up under other approaches: such approaches might capture cases of accentuation for which the present approach has no explanation.

2. We have treated all types of accent as equivalent. It is not clear, however, whether this is completely valid: future research might show that there are indeed functional differences between different types of pitch movement, irrespective of positional and melodic constraints.

\section{CONCLUSION}

The present results suggest that if the speaker can bring about a clear thematic structure in his discourse, he makes the distribution of accents dependent on it: expressions introducing a new topic are always accented. Once the topic is introduced the speaker often uses unaccented expressions, preferably pronouns. Expressions referring to other referents than the topic are often accented, especially at the beginning of a new thematic unit, even when the referent has been mentioned recently. One factor overruling this influence of thematic structure is contrast: expressions involved in a contrastive relation are generally accented. The distribution of accents within referring expressions may vary as a function of the linguistic context; for instance, if the same noun is used to refer to two different referents successively, the second instance of the noun is deaccented and an adjective or adverb is accented. This use of accentuation may help the listener to process the incoming speech efficiently.

\section{REFERENCES}

BOCK, J.K. and IRWIN, D.E. (1980). Syntactic effects of information availability in sentence production. Journal of Verbal Learning and Verbal Behavior, 19,467484.

BOLINGER, D. (1972). Accent is predictable (if you're a mind reader). Language, 48, 633-644.

BRESN AN, J. (1972). Stress and syntax: A reply. Language, 48, 326-342.

CHAFE, W.L. (1974). Language and consciousness. Language, 50, 111-133.

CномSKY. N. (1971). Deep structure, surface structure, and semantic interpretation. In D.D. Steinberg and L.A. Jakobovits (eds.), Semantics: An Interdisciplinary Reader in Philosophy. 
Linguistics and Psychology (Cambridge), pp. 183-216.

CLARK, H.H. and HA VILAND, S.E. (1977), Comprehension and the Given-New Contract. In R.O. Freedle (ed.), Discourse Processes: Advances in Research and Theory: Vol. 1. Discourse Production and Comprehension (Norwood), pp. $1-40$.

COLliER, R. and T HART, J. (1981). Cursus Nederlandse Intonatie (Leuven).

CUTLER, A. (1976). Phoneme monitoring reaction time as a function of preceding intonation contour. Perception and Psychophysics, 20, 5560.

CUTLER, A. and Fodor, J.A. (1979). Semantic focus and sentence comprehension. Cognition, 7. 49-59.

ERTEL, S. (1977). Where do the sentences of subjects come from? In S.S. Rosenberg (ed.), Sentence Production: Developments in Research and Theory (Hillsgate), pp. 141-167.

GARCIA, E. (1977). On the practical consequences of theoretical principles. Lingua, 43, 129-170.

GOODENOUGH-TREPA GNIER, C. (1977). Etude psycholinguistique sur la focalisation, In R. Sarassin (ed.), Psycholinguistique expérimentale (Montréal), pp. 129-144.

GoOdenOUGH-TREPAGNIER, C. and SMITH, F. (1977). Thematization and intonation in the organization of sentences, Language and Speech, 20, 99-107.

Grosz, B. J. (1978). Discourse knowledge. In D.E. Walker (ed.), Understanding Spoken Language (New York), pp. 227-344.

HALLIDAY, M.A.K. (1967). Notes on contrastivity and theme Il. Journal of Linguistics, 3, 199-244.

T HAR T, J. and COHEN, A. (1973). Intonation by rule: A perceptual quest. Journal of Phonetics, 1. 309-327.

'T HAR T. J. and COLLIER, R. (1975). Integrating different levels of intonation analysis. Journal of Phonetics, 3, 235-255.

KARMILOFF-SMITH, A. (1981). The grammatical marking of thematic structure in the development of language production. In W. Deutsch (ed.), The Child's Construction of Language (London), pp. 121-147.

KeIJSPER, C.E. (1982). Over de relatie tussen context en accentuatie. Forum der Letteren, 23. $31-45$.

KIRSNER, R.S. (1979). Deixis in discourse: An exploratory quantitative study of the modern Dutch demonstrative adjectives. In T. Givón (ed), Syntax and Semantics: Vol. 12. Discourse and Syntax (New York), pp. 355-375.

LADD, D.R. (1978). The Structure of Intonational Meaning (Bloomington).

LEHISTE, I. (1970). Suprasegmentals (Cambridge, Mass.).

LINDE, C. (1977). Focus of attention and the choice of pronouns in discourse. Paper presented at the Symposium on Discourse and Syntax (University of California, Los Angeles).

MARSLEN WiLSON, W., LEVY, E. and TYLER, L.K. (1982). Producing interpretable discourse: The establishment and maintenance of reference. In R. Jarvella and W. Klein (eds.), Speech, Place, and Action (London), pp. 339-378.

NOOTEBOOM, S.G. and TERKEN, J.M.B. (1982). What makes speakers omit pitch accents? An experiment. Phonetica, 39, 317-336.

OSGOOD. C.E. and BOCK, KJ. (1977). Salience and sentencing. In S.S. Rosenberg (ed.), Sentence Production: Developments in Research and Theory (Hillsgate), pp. 81-140.

PEChmanN, T. (1981). Children's assignment of acoustic stress in referential communication. In Papers and Reports on Child Language Development: Vol. 21 (Stanford University), pp. 100-107.

REICHMAN, R. (1978). Conversational coherency. Cognitive Science, 2, 283-327.

SCHMERLING, S.F. (1976). Aspects of English Sentence Stress (Austin).

O'ShAUGHNESSY, D. (1976). Modelling fundamental frequency, and its relationships to syntax, semantics, and phonetics. Ph.D. dissertation Cambridge University.

THORSEN. N. (1980). Neutral stress, emphatic stress, and sentence intonation in advanced standard Copenhagen Danish. Annual Report of the Institute of Phonetics, University of Copenhegen, 14, 121-205. 


\section{ADDRESSES OF CONTRIBUTORS}

BAPTISTA. Professor Barbara Oughton, Departamento de Língua e Literatura Estrangeiras, Universidade Federal de Santa Catarina, Campus Universitário, Trinidade, 88.000 Florianópolis, Santa Catarina, Brazil.

Klecan-AKer, Dr. Joan S., Program in Communication Disorders, University of Houston, University Park, Houston, TX 77004, U.S.A.

Owings, Professor Nathaniel O., Dept. of Speech Communication, Montana State University, Bozeman, Montana 59717, U.S.A.

Ragsdale, Professor J. Donald, Dept. of Speech Communication, Louisiana State University, Baton Rouge, LA 70803, U.S.A.

REPP, Dr. Bruno H., Haskins Laboratories, 270 Crown Street, New Haven, CT 06511-6695, U.S.A.

Scherer, Dr. Nancy J., Director, Speech-Language Services, Providence Speech and Hearing Center, 1301 Providence Avenue, Orange, CA 92668, U.S.A.

Sister heN, Mr. Daniel H., 28 Billyday, Kenner, LA 70062, U.S.A.

TERken, Mr. Jacques M.B., Institute for Perception Research, P.O. Box 513, 5600 MB Eindhoven, The Netherlands.

\section{Publications Received}

Al-Ani, Salman, Fred W. Householder Bibliography, Eurolingua, (1984), Bloomington, ID 474020101 , U.S.A.

Elert, Claes-Christian, Johansson, Vréne, and Strangert, Eva, (eds.), Nordic Prosody III, Papers from a Symposium, Ume Studies in the Humanities 59 (Acta Universitatis Umensis 1984), Stockholm, Sweden.

International Journal of the Sociology of Language, 47 (1984).

Journal of Experimental Psychology: Animal Behavior Processes, 10 (1984), 3.

Journal of Experimental Psychology: General, 113 (1984), 3.

Journal of Experimental Psychology: Human Perception and Performance, $10(1984), 4$.

Journal of Experimental Pyychology: Learning. Memory, and Cognition, 10 (1984), 3.

Süpostavitelno Ezikoznanié. 9 (1983), 5,6;9 (1984), 1 .

Zurnal Vysíej Nervoj Dejatelnosti. 34 (1984), 3. 